Published in final edited form as:

Org Lett. 2006 October 12; 8(21): 4903-4906.

\title{
Oxonitriles: A Grignard Addition-Acylation Route to Enamides
}

\author{
Fraser F. Fleming, Guoqing Wei, Zhiyu Zhang, and Omar W. Steward \\ Department of Chemistry and Biochemistry, Duquesne University, Pittsburgh, PA 15282-1530, \\ flemingf@duq.edu
}

\section{Abstract}

Sequential addition of three different Grignard reagents and pivaloyl chloride to 3-oxo-1cyclohexene-1-carbonitrile installs four new bonds to generate a diverse array of cyclic enamides. Remarkably, formation of the $\mathrm{C}$-magnesiated nitrile intermediate is followed by preferential acylation by pivaloyl chloride rather than consumption by in situ Grignard reagent. Rapid N-acylation of the C-magnesiated nitrile generates an acyl ketenimine that reacts readily with Grignard reagents, or a trialkyl zincate, effectively assembling highly substituted, cyclic enamides.

Cyclic oxonitriles incorporate chemically distinct functionalities ideally suited for multicomponent reactions. ${ }^{1}$ Historically, the synergistic reactivity of oxonitriles was first harnessed in regioselective Robinson annulations ${ }^{2}$ and elegently employed in several natural product syntheses. ${ }^{3}$ Subsequently, zipper reactions, ${ }^{4}$ addition-fragmentations,${ }^{5}$ and cycloadditioncycloreversion 6 reactions have exploited oxonitriles in domino reaction sequences for rapidly installing high molecular complexity.

Unsaturated cyclic oxonitriles incorporate three different functionalities capable of selective deployment en route to highly substituted cyclic nitriles (Scheme 1). ${ }^{7}$ Addition of excess methylmagnesium chloride to 3 -oxo-1-cyclohexene-1-carbonitrile (1) ${ }^{8}$ affords the Cmagnesiated nitrile $\mathbf{2}$ that alkylates a diverse range of electrophiles. Intriguingly, alkylations of the C-magnesiated nitrile $\mathbf{2}$ are stereoelectronically controlled, with alkyl halide and sulfonate electrophiles alkylating with retention of stereochemistry $(\mathbf{2} \rightarrow \mathbf{3})$, and aldehyde and acyl cyanide electrophiles alkylating with inversion of stereochemistry $(\mathbf{2} \rightarrow \mathbf{4}) .{ }^{9}$ Synthetically, the addition-alkylation installs three new stereocenters in which the stereochemistry of the nitrile-bearing carbon can be controlled through judicious choice of electrophile.

Remarkably, alkylating the C-magnesiated nitrile 2 with methyl chloroformate affords neither of the nitriles 3 or $\mathbf{4}$. Adding excess $\mathrm{MeMgCl}$ to oxonitrile $\mathbf{1}$ and intercepting $\mathbf{2}$ with excess methyl chloroformate, led to the incorporation of three new carbonyl functionalities and complete loss of the $\mathrm{C} \equiv \mathrm{N}$ functionality! Spectral analysis identified the product as the enamide 7 (Scheme 2), presumably resulting from a rare ${ }^{10} \mathrm{~N}$-acylation of the $\mathrm{C}$-magnesiated nitrile 2. Rapid addition of excess $\mathrm{MeMgCl}$ to the transient ${ }^{11}$ acyl ketenimine ${ }^{12} \mathbf{5}$ followed by sequential $\mathrm{N}$ - and $\mathrm{O}$-acylation of the resulting magnesiated enamide $\mathbf{6}$, leads to the enamide 7. Overall, the Grignard addition-acylation sequence installs six new bonds in one synthetic operation!

Experimentally, only two of the three equivalents of $\mathrm{MeMgCl}$ are consumed by the oxonitrile 1 prior to the addition of methyl chloroformate. Consequently, at $-78^{\circ} \mathrm{C}$ methyl chloroformate must react more slowly with $\mathrm{MeMgCl}$ than with the metalated nitrile 2 ! Armed with the speculation that methyl chloroformate might react competitively with $\mathrm{MeMgCl}$ and the 
metalated nitrile $\mathbf{2}$, the reaction was repeated with excess pivaloyl chloride as a larger, more chemoselective electrophile. ${ }^{13}$ Indeed, acylating 2 with excess pivaloyl chloride at $0{ }^{\circ} \mathrm{C}$ affords enamide $8 \mathbf{a}$ considerably more efficiently (Table 1 , entry 1$).{ }^{14}$

Sequential addition of three different Grignard reagents and pivaloyl chloride to oxonitrile $\mathbf{1}$ generates a diverse array of substituted enamides (Table 1). ${ }^{15}$ Significant diversity is achieved through the sequential addition of three different Grignard reagents: to the carbonyl group, the alkenenitrile, and the acyl ketenimine. Effectively, the strategy provides excellent control over the substitution pattern simply by varying the addition order (Table 1, compare entry 4 with entry 8). Grignard reagents with $\mathrm{sp}^{3} \mathrm{or} \mathrm{sp}^{2}$ hybridization of the carbon-magnesium bond are required for the conjugate addition whereas the nucleophilic attack on the reactive acyl ketenimine tolerates all hybridization types.

Nucleophilic attack on the acyl ketenimine intermediates generate highly congested enamides. $\mathrm{X}$-ray crystallography ${ }^{16}$ of $\mathbf{8 b}$ and $\mathbf{8 g}$ secures an enamide geometry consistent with a nucleophilic addition of Grignard reagents to the more accessible face of the acyl ketenimine intermediate 9 (Scheme 3). ${ }^{17}$ The resulting enamides experience considerable steric compression between the amide nitrogen and the allylic substituent as illustrated in the crystal structure for $8 \mathbf{g}$ where the steric interaction is relieved in a chair conformation with the phenyl substituent in an axial orientation (Figure 1). ${ }^{18}$

Attempts to isolate the putative acyl ketenimine 9 provided key mechanistic insight (Scheme 3 ). Addition of excess pivaloyl chloride in the absence of a Grignard reagent failed to afford the acyl ketenimine $9(\mathrm{H}=\mathrm{MgCl})$, which is consistent with the instability of this reactive species. ${ }^{11}$ Presumably, a slow reaction of pivaloyl chloride with Grignard reagents permits rapid interception of the acyl ketenimine by the nucleophilic organomagnesium reagent immediately upon formation. In some instances, acylation of the C-magnesiated nitrile is slow, resulting in removal of the pivaloyl chloride by the Grignard reagent. In these cases (Table 1, entries 7 and 9) the portion-wise addition of Grignard reagent and pivaloyl chloride permits higher conversions.

The instability, and presumed high reactivity, of the acyl ketenimine 9 suggested intercepting this electrophile with less nucleophilic organometallics. Intercepting 9 with $\mathrm{Et}_{2} \mathrm{Zn}$ in the presence of pivaloyl chloride affords the expected enamide $\mathbf{8 j}$, although in a disappointing $11 \%$ yield (Scheme 3). Assuming $\mathrm{Et}_{2} \mathrm{Zn}$ to be insufficiently reactive, the portion-wise addition was repeated with a mixed trialkylzincate formed by adding $\mathrm{Me}_{3} \mathrm{SiCH}_{2} \mathrm{Li}$ to $\mathrm{Et}_{2} \mathrm{Zn} .{ }^{19}$ Selective transfer of the ethyl group led to formation of the enamide $\mathbf{8 j}$ in $63 \%$ yield.

Sequential addition of three different Grignard reagents and pivaloyl chloride to 3-oxo-1cyclohexene-1-carbonitrile (1) generates a diverse array of cyclic enamides. An intrinsic feature of the $\mathrm{N}$-acylation is the preferential reaction of pivaloyl chloride with the $\mathrm{C}$ magnesiated nitrile intermediate rather than with a Grignard reagent! Rapid $\mathrm{N}$-acylation of the $\mathrm{C}$-magnesiated nitrile generates an acyl ketenimine that reacts readily with a Grignard reagent or a trialkyl zincate. Overall, the Grignard addition-acylation with pivaloyl chloride installs four new bonds and provides an effective route to highly substituted, cyclic enamides.

\section{Supplementary Material}

Refer to Web version on PubMed Central for supplementary material.

\section{Acknowledgements}

Financial support from the National Institutes of Health (2R15AI051352), and in part from the National Science Foundation (CHE 0515715, CRIF 024872), is gratefully acknowledged, as is assistance from Dr. Charles Campana, Bruker AXS Inc., in solving the X-ray structure of $\mathbf{8 b}$. 


\section{References}

1. Fleming FF, Iyer P. Synthesis 2006:893.

2. For Robinson annulations with $\beta$-oxonitriles see: (a) Reference 1. (b) Varner MA, Grossman RB. Tetrahedron 1999;55:13867. (c) Gawley RE. Synthesis 1976:777. (d) Jung ME. Tetrahedron 1976;32:3. For Robinson annulations with $\gamma$-oxonitriles see: (e) Sobolev A, Vos M, Zuilhof HT, Sarabèr CE, Jansen BJM, de Groot A. Arkivoc 2005:39. (f) Swarts HJ, Verstegen-Haaksma AA, Jansen BJM, de Groot A. Tetrahedron 1994;50:10083. (g) Verstegen-Haaksma AA, Swarts HJ, Jansen BJM, de Groot A. Tetrahedron 1994;50:10073. (h) Inubushi Y, Kikuchi T, Ibuka T, Tanaka K, Saji I, Tokane K. Chem Pharm Bull 1974;22:349. (i) Loewenthal HJE. Isr J Chem 1966;4:31.

3. For recent examples see: (a) Liu HJ, Ly TW, Tai CL, Wu JD, Liang JK, Guo JC, Tseng NW, Shia KS. Tetrahedron 2003;59:1209. (b) Olkhovik V, Masalov N, Jansen BJM, Groot A de. Tetrahedron Lett 2001;42:4903.

4. (a) Ivancev W, Ognyanov VI, Hesse M. Tetrahedron 1996;57:4363. (b) Ognyanov VI, Hesse M. Helv Chim Acta 1990;73:272. (c) Ognyanov VI, Hesse M. Helv Chim Acta 1989;72:1522.

5. Cocker W, Grayson DH, Shannon PVR. J Chem Soc Perkin Trans 1995;1:1153.

6. (a) Aundenaert F, Keukeleire D De, Vandewalle M. Tetrahedron 1987;43:5593. (b) Keukeleire, D De; Audenhove, M Van; Hijfte, L Van; Audenaert, F.; Vandewalle, M. J Photochem 1985;28:165.

7. Fleming FF, Zhang Z, Wang Q, Steward OW. Angew Chem Int Ed 2004;43:1126.

8. Fleming FF, Zhang Z, Wei G. Synthesis 2005:3179.

9. (a) Fleming FF, Zhang Z, Wei G, Steward OW. J Org Chem 2006;71:1430. [PubMed: 16468790] (b) Fleming FF, Zhang Z, Wei G, Steward OW. Org Lett 2005;7:447. [PubMed: 15673261]

10. Metalated nitriles alkylate almost exclusively on carbon with silyl ${ }^{\mathrm{a}-\mathrm{e}}$ and acetyl chlorides ${ }^{\mathrm{f}}$ being virtually the only electrophiles with a propensity for reaction on nitrogen: (a) Kawakami Y, Hisada H, Yamashita Y. Tetrahedron Lett 1985;26:5835. (b) Differding E, Vandevelde O, Roekens B, Van TT, Ghosez L. Tetrahedron Lett 1974;28:397. (c) Watt DS. Synth Commun 1974;4:127. (d) Kruger CR, Rochow EG. Angew Chem Int Ed 1963;2:617. (e) Prober M. J Am Chem Soc 1956;78:2274. (f) Enders D, Kirchhoff J, Gerdes P, Mannes D, Raabe G, Runsink J, Boche G, Marsch M, Ahlbrecht H, Sommer H. Eur J Org Chem 1998:63.

11. Attempts to detect the intermediate acyl ketenimine have not been successful, consistent with their known instability: (a) Reference 10f. (b) Finnerty J, Mitschke U, Wentrup C. J Org Chem 2002;67:1084. [PubMed: 11846648] (c) Meier S, Wuerthwein EU. Chem Ber 1991;124:2339. (d) Schweng J, Zbiral E. Monatsh Chem 1976;107:537.

12. Alajarín M, Vidal A, Tover F. Targets Heterocycl Syst 2000;4:293.

13. Attempts to intercept 2 with acryloyl chloride were not successful.

14. The $\mathrm{N}$-acylation of 2 with pivaloyl chloride implies that methyl chloroformate acylates first on nitrogen and then on oxygen as shown (Scheme 2).

15. General Grignard Addition-Acylation procedure: A THF solution of $\mathrm{MeMgCl}$ (1.05-1.1 equiv) was added to $\mathrm{a}-15^{\circ} \mathrm{C}$ THF solution $(0.1 \mathrm{M})$ of oxonitrile 1 . After $2 \mathrm{~h}$, a THF solution of a second Grignard reagent ( 1.5 equiv) was added and then the solution was allowed to warm to room temperature. After $2 \mathrm{~h}$, the solution was cooled to $0{ }^{\circ} \mathrm{C}$ followed by the sequential addition of a THF solution of the third Grignard reagent (4.0 equiv) and pivaloyl chloride (6.0 equiv). After $1 \mathrm{~h}$ at $0{ }^{\circ} \mathrm{C}$ the solution was warmed to room temperature and stirred for $1 \mathrm{~h}$. Subsequent addition of saturated, aqueous $\mathrm{NH}_{4} \mathrm{Cl}$ and extraction with EtOAc afforded a crude product that was washed with brine and dried $\left(\mathrm{MgSO}_{4}\right)$, concentrated and purified by radial chromatography to afford the pure enamide.

16. X-ray crystallography of $8 \mathrm{~b}$ and $8 \mathrm{~g}$ confirmed the stereochemical assignment. The authors have deposited the crystallographic data for $8 \mathrm{~b}$ and $8 \mathrm{~g}$ with the Cambridge Crystallographic Data Center (CCDC 605398 and 605397, respectively). The supplementary crystallographic data can be obtained free of charge via www.ccdc.cam.ac.uk/conts/retrieving.html or from the Cambridge Crystallographic Data Center, 12 Union Road, Cambridge CB2 1EZ, UK (fax +44 1223 336033; or deposit@ccdc.cam.ac.uk.).

17. Battaglia A, Cainelli G, Giacomini D, Martelli G, Panunzio M. Tetrahedron Lett 1987;28:4347.

18. The unit cell contains three distinct conformers: the conformer shown in Figure 1, a second similar conformer in which the phenyl group is axial, and a third conformer with a ring-flipped cyclohexane 
ring in which the phenyl sustituent is equatorially oriented. An ORTEP diagram is provided in the Supporting Information.

19. (a) Musser CA, Richey HG Jr. J Org Chem 2000;65:7750. [PubMed: 11073576] (b) Westerhausen M, Wieneke M, Ponikwar W, Nöth H, Schwarz W. Organometallics 1998;17:1438. (c) Purdy AP, George CF. Organometallics 1992;11:1955. 


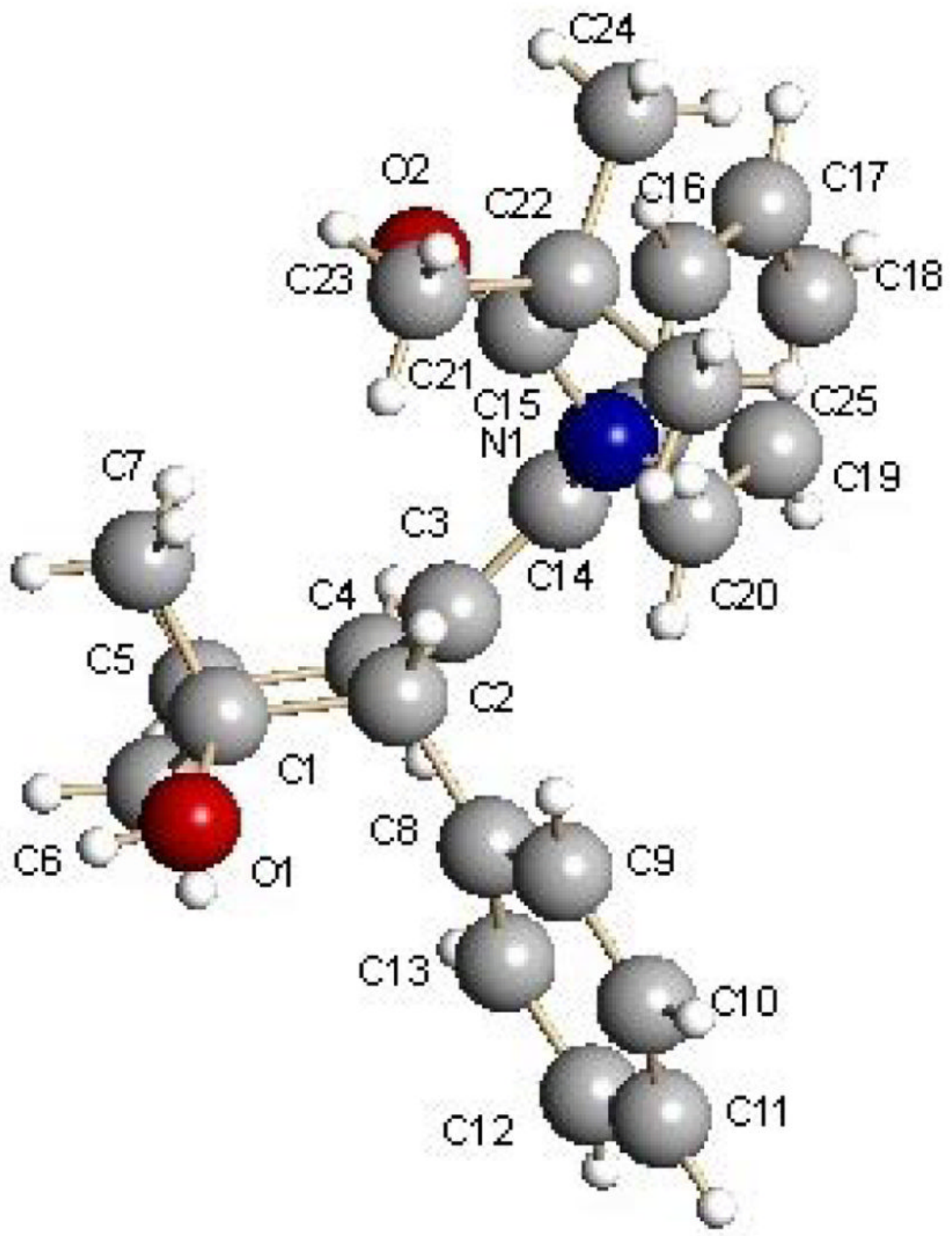

Figure 1.

Crystallographic structure of enamide $\mathbf{8 g}$ 


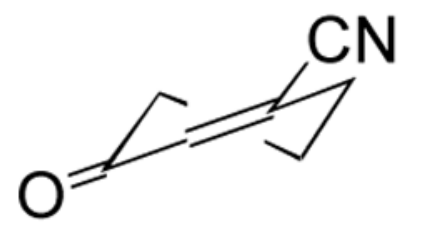

1
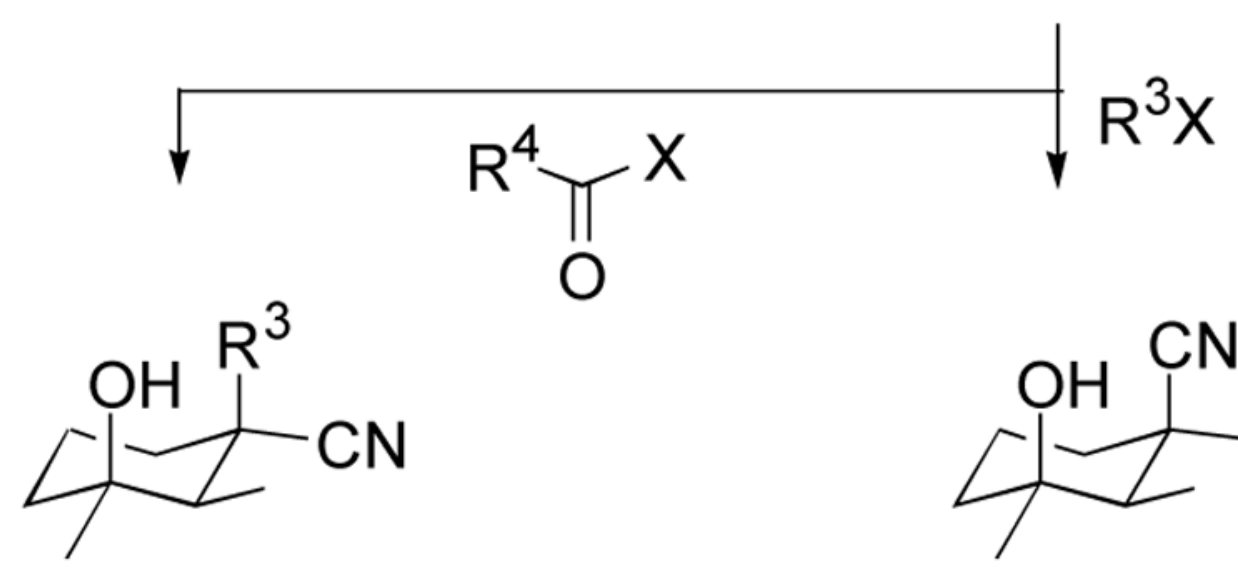

3 Retention

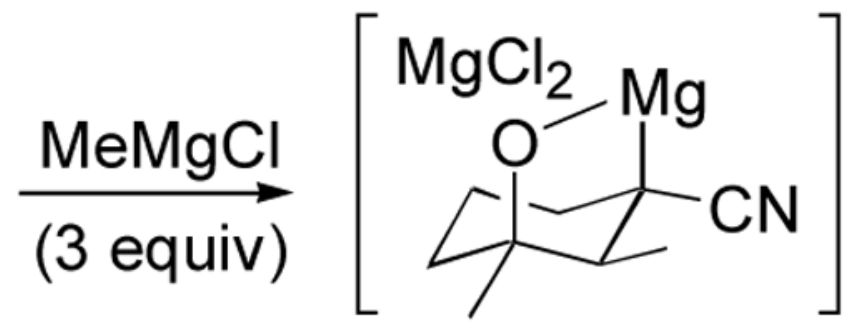

2

O

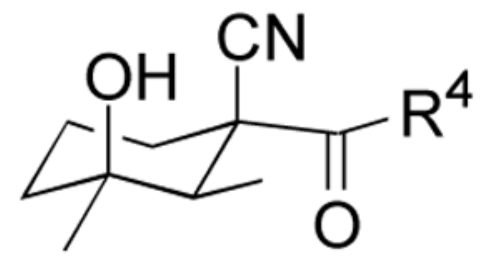

4 Inversion

Scheme 1.

Grignard Addition-Alkylations of Oxonitrile 1. 


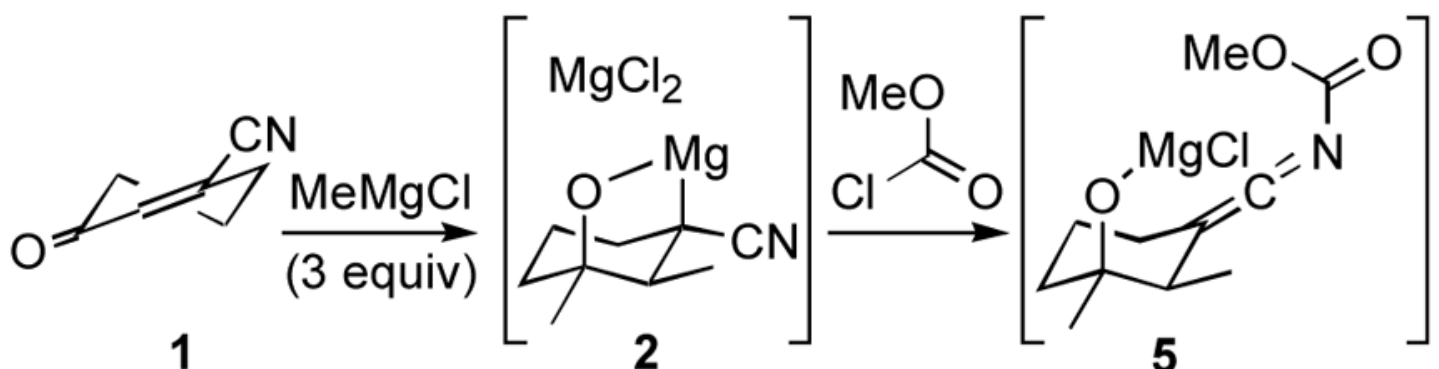
1

2

5

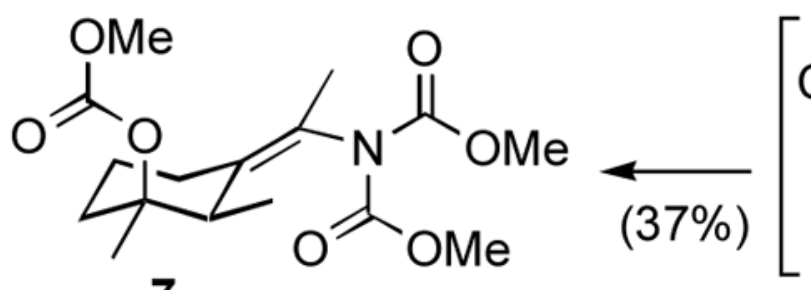
7<smiles>COCC1(C)CCC2(C)C(C)=C(OC)C1C2=C(C)N(C)Cl</smiles>

6

Scheme 2.

Grignard Addition-Acylation of Oxonitrile 1. 


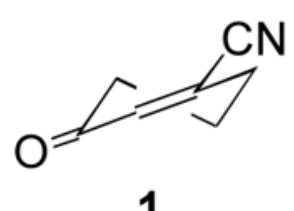

1<smiles>CCC(=O)[Te]C(=O)NC(CC)=C1CC2(C)CCC(C)C1C2</smiles>

$8 j$

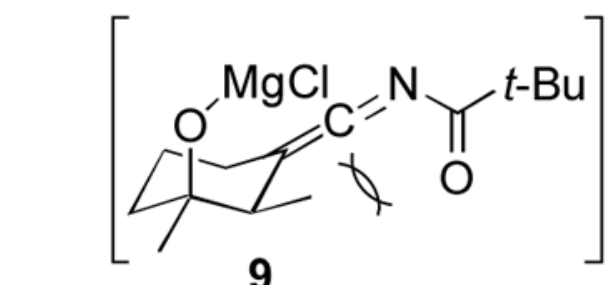

$\mathrm{Me}_{3} \mathrm{SiCH}_{2} \mathrm{ZnEt}_{2} \mathrm{Li} \downarrow$

Scheme 3.

Organozinc Addition-Acylation

10

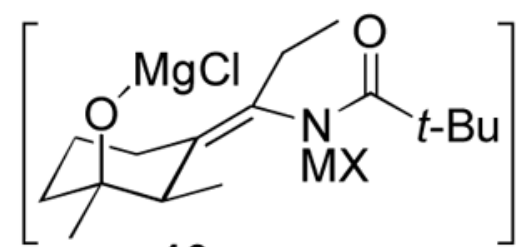


Table 1

Oxonitrile Addition-Acylation Enamides Synthesis

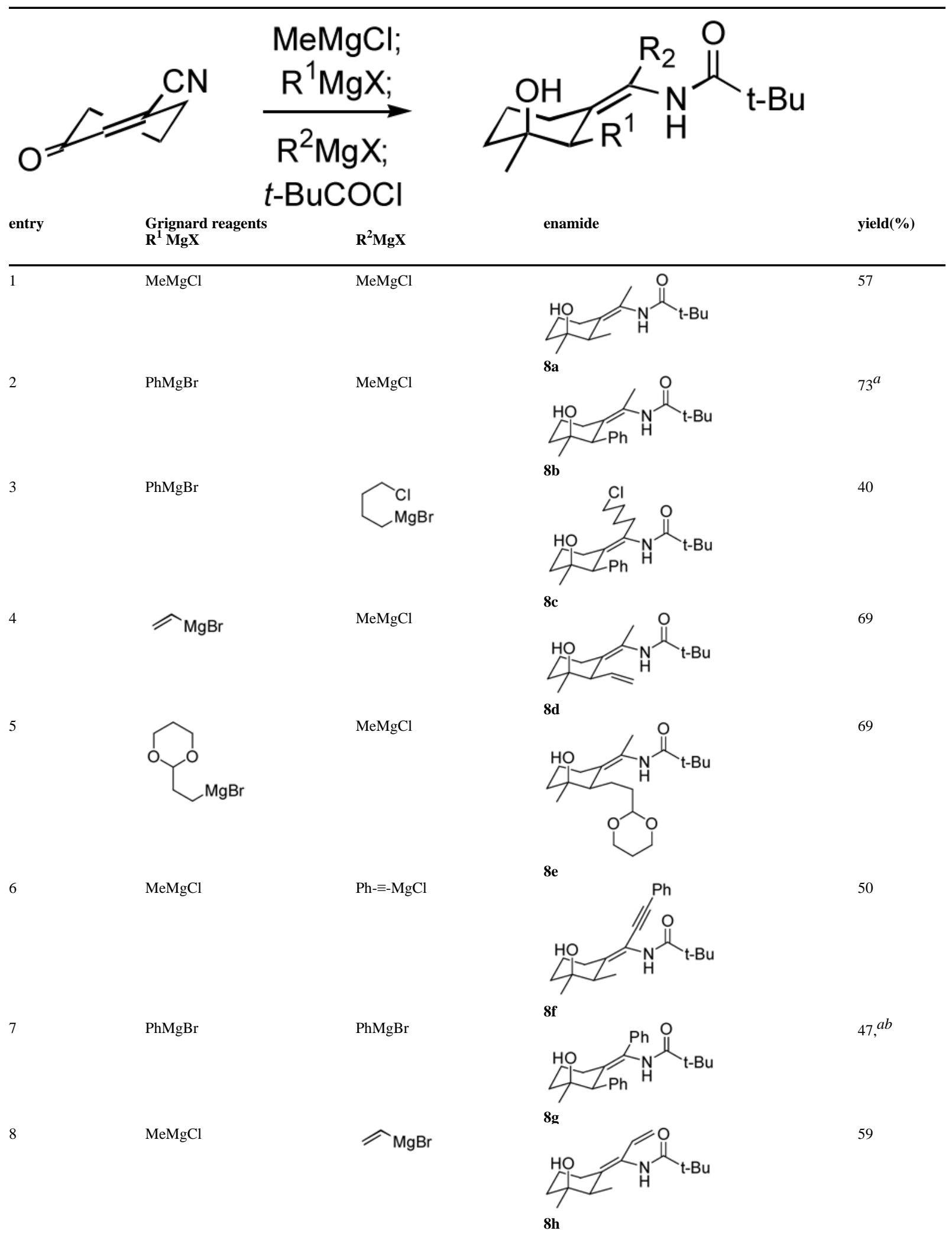

Org Lett. Author manuscript; available in PMC 2008 August 21. 


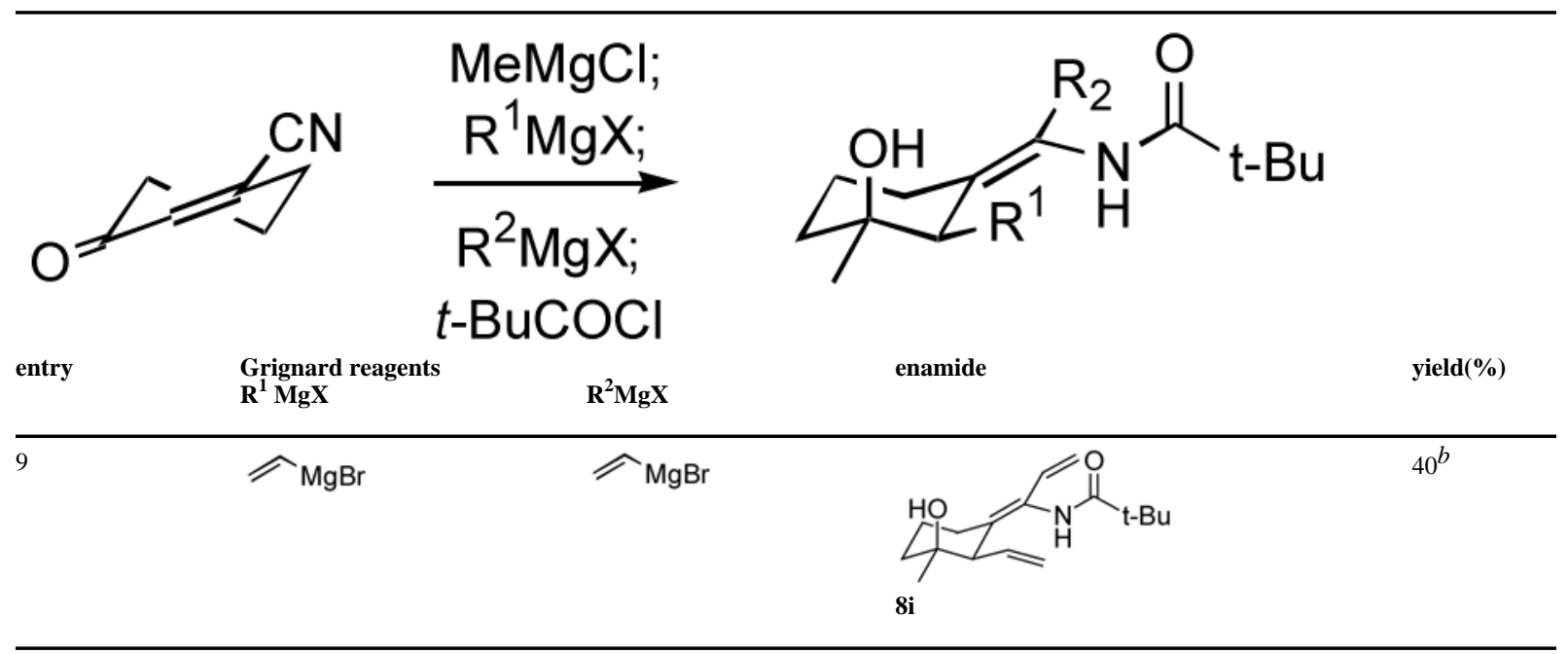

$a_{\text {The structure was confirmed by x-ray crystallography. } 16}$

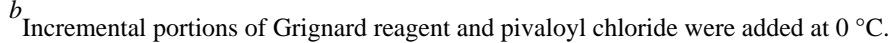

